\title{
Angelo Giuseppe Roncalli, Étienne Fouilloux, (introd., annot.), Journal de France. Tome 2,
} 1949-1953

Paris, Édition du Cerf, 2008, 644 p.

\section{Frédéric Gugelot}

\section{(2) OpenEdition \\ Journals}

\section{Édition électronique}

URL : http://journals.openedition.org/assr/21184

DOI : $10.4000 /$ assr. 21184

ISSN : $1777-5825$

\section{Éditeur}

Éditions de l'EHESS

\section{Édition imprimée}

Date de publication : 31 décembre 2009

Pagination : 75-342

ISBN : 978-2-7132-2218-4

ISSN : 0335-5985

\section{Référence électronique}

Frédéric Gugelot, « Angelo Giuseppe Roncalli, Étienne Fouilloux,(introd., annot.), Journal de France. Tome 2, 1949-1953 », Archives de sciences sociales des religions [En ligne], 148 | octobre-décembre 2009, document 148-117, mis en ligne le 03 février 2010, consulté le 21 septembre 2020. URL : http:// journals.openedition.org/assr/21184; DOI : https://doi.org/10.4000/assr.21184 


\section{Angelo Giuseppe Roncalli, Étienne Fouilloux,(introd., annot.), Journal de France. Tome 2, 1949-1953}

Paris, Édition du Cerf, 2008, 644 p.

Frédéric Gugelot

\section{RÉFÉRENCE}

Angelo Giuseppe Roncalli, Étienne Fouilloux, (introd., annot.), Journal de France. Tome 2, 1949-1953, Paris, Édition du Cerf, 2008, 644 p.

1 En 2006, paraissait le premier volume du journal tenu par le nonce Roncalli, futur pape sous le nom de Jean XXIII, lors de sa mission française. Voici le second et dernier. Heureusement pour le lecteur, Roncalli étant resté fidèle à sa prise de note elliptique, l'ouvrage s'éclaire grâce à l'immense appareil de notes d'Étienne Fouilloux.

2 S'il fallait dresser un profil de ces années de nonciature, la photographie de couverture, qui nous livre les doubles rondeurs de Roncalli et d'Édouard Herriot, montre cette activité apaisée du nonce dans une France elle-même pacifiée. D'autant que les élections de 1951 montrent un glissement à droite du pays qui satisfait le si conservateur nonce. Le retour à l'ordre tant politique que religieux d'après la Libération convient très bien à Roncalli. Les relations avec les politiques resteront cordiales jusqu'à son départ. En 1952, il offre même au président de la République, Vincent Auriol, le livre de Guareschi, Le Petit monde de don Camillo. Les interventions politiques du nonce sont rares mais sur la question scolaire, il joue un véritable rôle de lobbying. Le gouvernement fait appel à lui pour calmer l'ardeur des combattants de l'école privée, en 1950, tandis qu'il observe avec espoir les lois Marie et Barangé, si favorables au financement de ces écoles, retardant même son séjour en Italie jusqu'à la certitude du vote. 
3 Les années 1949-1953 ne changent pas le portait du nonce que dessinent les premières années. Il poursuit sa politique d'atténuation des effets de l'épuration ecclésiale et se félicite quand un disgracié retrouve une place ou obtient une promotion à l'exemple de Mgr Feltin devenant, en 1949, archevêque de Paris. Ses envies de voyages ne sont pas réfrénées. En 1950, il est cent cinquante et un jours hors de Paris. Ses séjours lui permettent néanmoins de bien connaître le catholicisme français même si aucune des audaces pastorales ou spirituelles ne trouve son soutien. Mais le journal n'évoque jamais, ce qui ne veut rien dire, les mouvements progressistes. En 1950, on ne trouve rien sur l'affaire de la Quinzaine ; les prêtres ouvriers sont eux aussi peu présents : « 28 juin 1951: À l'inverse, les prêtres-ouvriers apparaissent plus que jamais en contradiction avec l'esprit sacerdotal. Actuellement, le Saint-Siège met en place les règles voulues; je ne crois pas qu'ils pourront s'y conformer ». La nonciature continue d'accueillir favorablement les courants les plus intransigeants et à droite du catholicisme français, même si une lente prise de distance avec ses interlocuteurs perce au début des années cinquante. Roncalli mène une politique de relatif équilibre mais s'inquiète des critiques qui se multiplient contre l'Église. La prudence domine la rédaction de ces agendas sans que s'explique ce comportement envers un document si intime.

Il se méfie des nouveautés intellectuelles du catholicisme français et rejette vigoureusement les avancées esthétiques. Ainsi le 6 août 1952, il condamne le Christ de Germaine Richier. Mais les épanchements personnels sont rares, le nonce se livre peu. Il apparaît comme un prêtre tridentin à la piété classique. C'est peu dire que Jean XXIII ne perce pas sous Roncalli. Preuve supplémentaire que la grâce d'état existe.

À signaler le prix exorbitant de l'ouvrage, sans illustrations, photos ou cartes : 84 euros. 